\title{
Rice Area Estimation using Sentinel 1A SAR Data in Cauvery Delta Region
}

\author{
Sugavaneshwaran Kannan ", Ragunath Kaliaperumal, S. Pazhanivelan, \\ R. Kumaraperumal and K. Sivakumar \\ Department of Remote Sensing \& GIS, Tamil Nadu Agricultural University, \\ Coimbatore, India \\ *Corresponding author
}

\section{A B S T R A C T}

\section{Keywords}

Rice, Synthetic Aperture Radar (SAR), Sentinel 1A, Crop area estimation, Multitemporal feature extraction

\section{Article Info}

Accepted:

07 January 2021 Available Online: 10 February 2021
A Research study was conducted to estimate the rice area in the Cauvery delta region of Tamil Nadu in the 2019 kharif season using Sentinel 1A SAR data by the multi-temporal feature extraction. Multi-temporal Sentinel 1A GRD data at VV and VH polarizations were obtained for the study area. These data were processed using MAPscape-RICE software. Sentinel $1 \mathrm{~A}$ is an active SAR microwave data, that captures the crop characteristics irrespective of the weather condition as well as illumination. Ground truth observations collected during the rice survey were used to derive the rice signature from the processed satellite images. The $\mathrm{dB}$ values extracted as signature were then subjected to the Multi-Temporal feature extraction method for delineating the rice-growing areas. Around 1,41,639 ha, 1,25,497 ha, and 1,17,703 ha were mapped as rice-growing areas in Thanjavur, Thiruvarur, and Nagapattinam districts, respectively. Accuracy assessment was done with 40 percent of the ground truth data. The overall classification accuracy was 93.1 percent with a kappa score of 0.86 .

\section{Introduction}

Rice is the major food crop in the world and it is the staple food for over 2.7 billion people. India have $44.6 \mathrm{~m}$ ha area in rice with 80 million tonnes of total cultivation. The Cauvery delta region has the maximum rice cultivated area than any other crops. Estimation of the rice area spatially will ensure the transfer of technologies and better policy decisions to sustain productions at various levels. Crop discrimination is the most important step for agricultural monitoring systems. With the latest advances in the remote sensing technologies, precise information on Crop area, Crop yield, Health, Damages and losses can be provided.

Usage of Optical remote sensing has been increased in crop monitoring. However, many images obtained at specific time of crop growth cycle are needed for reaching accuracy which limits the usage of optical data since cloud cover may prevent or delay the image acquisition during the crop growth stages. So, space borne SAR images can be 
used to observe the earth surfaces irrespective of the weather conditions and guarantees the temporal frequency of the images throughout the growing period (Boerner et al., 1987).

SAR data have a proven ability to detect the crop through unique temporal signature of the backscattered values exhibited by the crops. The usage of SAR backscattering values in Rice, Groundnut, Maize, Mango and Banana were demonstrated by successfully in identifying and discriminating the crops by Suga and Konishi (2008); Bouvet et al., (2009); Pazhanivelan et al., (2015); Mugilan et al., (2017); Ragunath et al., (2019) and Venkatesan et al., (2019).

The relationship between the crop characteristics and backscattering coefficient from various wavelengths are used to derive algorithms for estimating crop characteristics from SAR data. A fully automated processing chain module within MAPscape-RICE software was developed to convert the Multi temporal space-borne SAR data to terraingeocoded sigma-nought values. (Holecz et al., 2013).The main objective of the study is to estimate the rice cultivated area in Thanjavur, Thiruvarur and Nagapattinam districts of Tamil Nadu using SAR datasets.

\section{Materials and Methods}

\section{Study area}

Cauvery Delta Region lies in the eastern part of Tamil Nadu. It has a total geographic land area of 14.47 lakh ha. The Region comprised of Thanjavur, Thiruvarur, Nagapattinam occupies 57 percent of Cauvery Delta region followed by Tiruchirapalli, Ariyalur, Cuddalore and Pudukkottai districts. In this zone, Rice is the principal crop as cauvery delta region is considered as the Granary of Tamil Nadu. Hence Thanjavur, Thiruvarur, Nagapattinam districts from the Cauvery delta region were selected for studying the rice area.

\section{Satellite data}

Sentinel 1A imageries at $20 \mathrm{~m}$ resolution acquired at 12 days interval for months May to October of the year 2019.

\section{Ground truth collection}

Ground truth points were collected during the kharif season in the study area at different crop growth stages. Totally 200 rice points with non crop points have been collected for training and validation processes using random stratified sampling method.

\section{Pre-processing of SAR data}

A fully automated processing chain developed by Holecz et al., (2013) was used to convert SAR GRD multi-temporal data to terrain geocoded $\sigma^{\circ}$ values. The processing chain itself is a module within the MAPscape-RICE software. The basic processing includes the following steps.

Strip mosaicking: to facilitate the overall data processing and data handling,

Co-registration: Images acquired with the same observation geometry were co registered in slant range geometry,

Time-series speckle filtering: to balance differences in reflectivity between images,

Terrain geocoding: Radiometric calibration and normalization,

ANLD filtering: to get smoothened homogeneous targets,

Removal of atmospheric attenuation: $\sigma^{\circ}$ values were corrected by means of an interpolator. 


\section{Multi-temporal feature extraction}

Multi-temporal features viz., Minimum, Maximum, Mean, Minimum date, Maximum date and Span ratio of VV, VH polarization and Minimum, Maximum data were extracted using feature extraction tool in MAPscapeRICE software. These multi-temporal features are having certain range regarding rice crop, which were extracted using point sampling tool of QGIS 2.18.20.

\section{Crop classification}

The Aim of the image classification is to categorize the image pixels into a land cover categories based on the pixel value. This section explains the classification methodology used in this study for rice crop area identification and classification.

\section{Parameterized classification}

The Parameterized Classification algorithm quantitatively evaluates the variance and covariance of the category by spectral response pattern while classifying an unknown pixel. In this study, image classification was carried out using parameterized Classification algorithm with extracted multi-temporal features from GRD SAR images for the identification of rice. Values extracted from multi-temporal features for rice crop was used to create training polygons. The multi-temporal features used are $\mathrm{VH}_{\max }, \mathrm{VV}_{\text {min }}, \mathrm{VH}_{\text {maxDate }}, \mathrm{VV}_{\text {minDate }}$, ccmin $(\mathrm{VV})$ and ccmean (VV).

\section{Accuracy assessment}

The Error matrix and Kappa statistics are used for evaluating the classification accuracy. The class allocation of each pixel in classified image is compared with the corresponding class allocation on reference data to determine the classification accuracy. The ground reference data are used for validation and the pixels of agreement and disagreement are compiled in the form of an error matrix. The accuracy measures, such as overall accuracy, producer's accuracy and user's accuracy were estimated. Kappa coefficient is another measure of classification accuracy. It is the measure of the proportional improvement by the classifier over a purely random assignment to classes.

\section{Results and Discussion}

With the innovations in remote sensing technique through microwave SAR (Synthetic Aperture Radar) data and the automated chain processing in crop identification and mapping, has become feasible. Freely available Sentinel 1A SAR data acquired at 12 days interval from May 2019 to October 2019 was used for the investigation in assessing rice crop identification and area estimation in the study area of Thanjavur, Thiruvarur and Nagapattinam districts of Tamil Nadu.

Temporal backscattering values were extracted for the ground truth points selected randomly over the study area. The backscattering values were found to be ranging from -15.99 to $-9.56 \mathrm{~dB}$ and -16.23 to $-6.32 \mathrm{~dB}$ in VV polarization at early and later stages respectively. In the case of $\mathrm{VH}$ polarization, the $\mathrm{dB}$ values were $-22.9 \mathrm{~dB}$ to $13.6 \mathrm{~dB}$ at early stage, $-23.1 \mathrm{~dB}$ to $11.8 \mathrm{~dB}$ at later stages.

The backscatter values were minimum at the early stage and maximum at later stages. The maximum, minimum and mean temporal backscattering values for Vertical-Vertical (VV) and Vertical-Horizontal (VH) polarized SAR data for Rice during the year in study districts were recorded and backscattering signature was generated (Fig. 1-4). 
Fig.1 Study area map

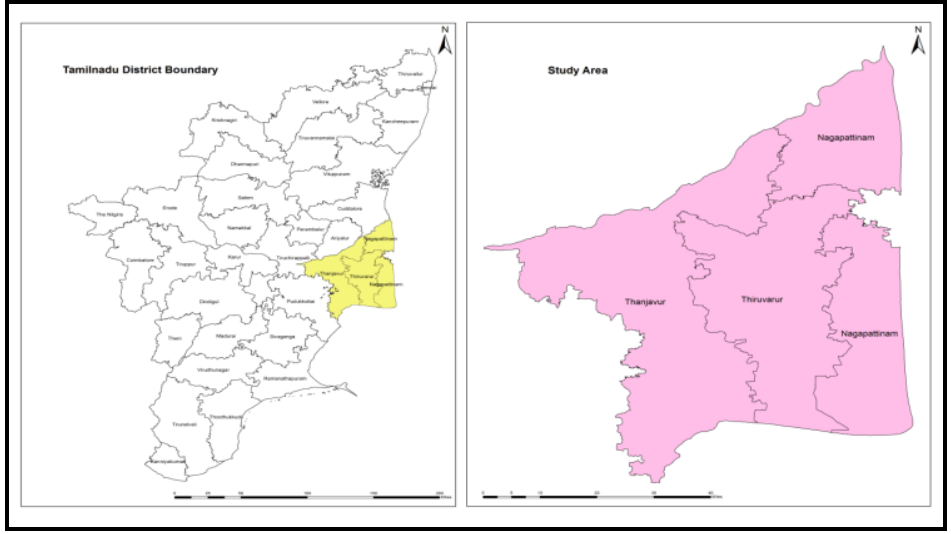

Fig.2 methodology flow chart

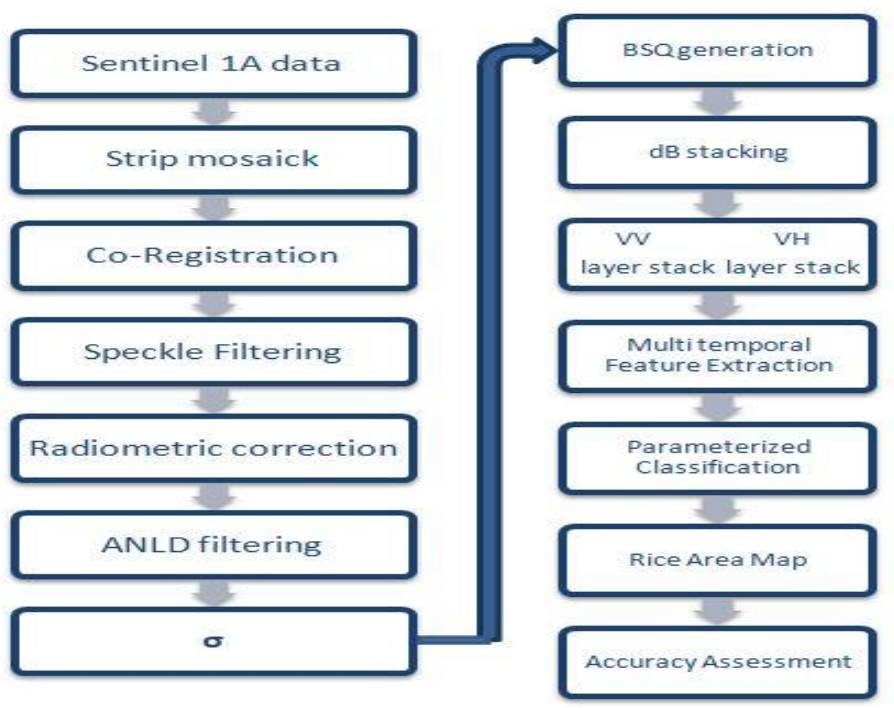

Fig.3 Rice temporal curve

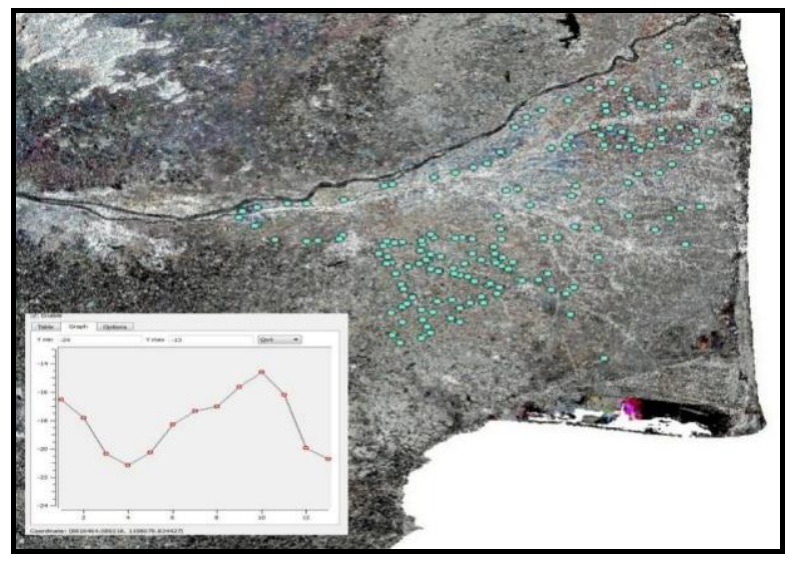


Fig.4 Rice area map of cauvery delta region

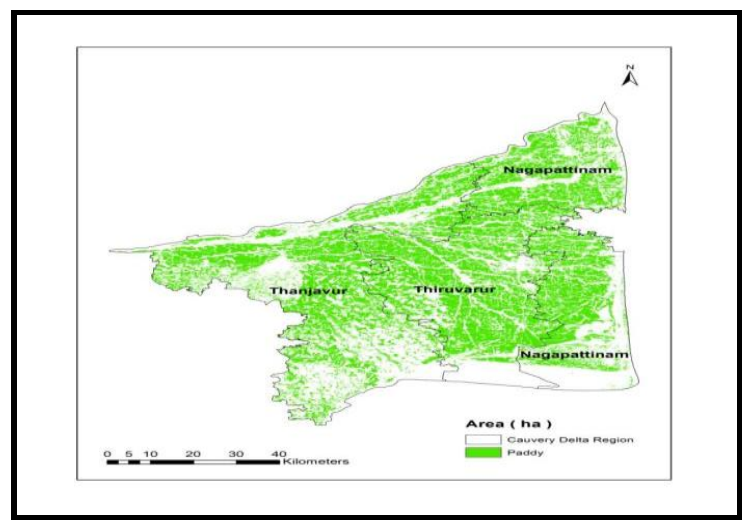

The estimated Rice area in Thanjavur district was 1,41,639 ha while in Thiruvarur district, it was $1,25,497$ ha and in Nagapattinam district, it was estimated to be $1,17,703$ ha.

Accuracy assessment: The rice area delineated using MTF (Multi-temporal Feature Extraction) method from SAR data was validated with the left over ground truth points. Around 170 Rice points and 32 NonRice sites were used to build the accuracy assessment through the confusion matrix. The results of the confusion matrix revealed that, the overall accuracy of the rice map was 93.1 percent with Kappa score of 0.86 .

In conclusion the identification and estimation of the rice area was accomplished from SAR satellite data with reliable accuracy in the study area revealing the possibility of using SAR data for area estimation. The unavailability of optical data for crop area estimation during extreme weather conditions and cloud cover could be conquered using SAR data. The obtained Crop area can be helpful for policy makers and in precision agriculture.

\section{Acknowledgement}

The authors sincerely thank The Department of Remote Sensing and GIS for providing the fund through SUFALAM scheme to carry out the research work in a project mode and also thank The Professor and Head and Staff members for their valuable comments and constructive suggestions on the manuscript.

\section{References}

Bouvet, A., Le Toan, T., and Lam-Dao, N. (2009). Monitoring of the rice cropping system in the Mekong Delta using ENVISAT/ASAR dual polarization data. IEEE transactions on geoscience and remote sensing, 47(2), 517-526.

Foo, B. Y., and Eom, H. J. (1987). Interpretation of the polarimetric copolarization phase tern in radar images obtained with the JPL airborne L-band SAR system. IEEE Transactions on Geoscience and Remote Sensing, (1), 77-82.

Holecz, F., Barbieri, M., Collivignarelli, F., Gatti, L., Nelson, A., Setiyono, T. D.,. .. and Pazhanivelan, S. (2013, September). An operational remote sensing based service for rice production estimation at national scale. In Proceedings of the living planet symposium.

Kaliaperumal, R., and GR, M. (2019). Mapping mango area using multitemporal feature extraction from Sentinel 1A SAR data in Dharmapuri, Krishnagiri and Salem districts of Tamil 
Nadu. Madras

Journal, 106.

Raman, M. G., Kaliaperumal, R., and Pazhanivelan, S. (2017). Rice Area Estimation in Tiruvarur District of TamilNadu using VV Polarized Sentinel 1A SAR Data. Indian Journal of Natural Sciences, 8(44), 12782-12793.

Pazhanivelan, S., Kannan, P., Mary, P. C. N., Subramanian, E., Jeyaraman, S., Nelson, A., and Yadav, M. (2015). Rice crop monitoring and yield estimation through COSMO Skymed and TerraSAR-X: A SAR-based experience in India. The International Archives of Photogrammetry, Remote Sensing and Spatial Information Sciences, 40(7), 85.
Suga, Y., and Konishi, T. (2008, October). Rice crop monitoring using $\mathrm{X}, \mathrm{C}$ and $\mathrm{L}$ band SAR data. In Remote Sensing for Agriculture, Ecosystems, and Hydrology X (Vol. 7104, p. 710410). International Society for Optics and Photonics.

Venkatesan, M., Pazhanivelan, S., and Sudarmanian, N. S. (2019). MULTITEMPORAL FEATURE EXTRACTION FOR PRECISE MAIZE AREA MAPPING USING TIME-SERIES SENTINEL 1A SAR DATA. International Archives of the Photogrammetry, Remote Sensing and Spatial Information Sciences.

\section{How to cite this article:}

Sugavaneshwaran Kannan, Ragunath Kaliaperumal, S. Pazhanivelan, R. Kumaraperumal and Sivakumar, K. 2021. Rice Area Estimation using Sentinel 1A SAR Data in Cauvery Delta Region. Int.J.Curr.Microbiol.App.Sci. 10(02): 848-853. doi: https://doi.org/10.20546/ijcmas.2021.1002.100 